Research Paper

\title{
Effect of Ulcerative Colitis on Incidence of Colorectal Cancer: Results from the Nationwide Population-Based Cohort Study (2003-2013)
}

\author{
Jung-kyu Choi ${ }^{1}$, Dong-Wook Kim ${ }^{1}$, Sang-Yun Shin ${ }^{2}$, Eun-Cheol Park ${ }^{3 凶}$, Jung-Gu Kang ${ }^{凶}$ \\ 1. Institute of Health Insurance \& Clinical Research, National Health Insurance Service Ilsan Hospital, Goyang, Korea \\ 2. Department of Internal Medicine, National Health Insurance Service Ilsan Hospital, Goyang, Korea \\ 3. Department of Preventive Medicine \& Institute of Health Services Research, Yonsei University College of Medicine, Seoul, Korea \\ 4. Department of Surgery, National Health Insurance Service Ilsan Hospital, Goyang, Korea
}

$\square$ Corresponding authors: Eun-Cheol Park, MD, PhD, Department of Preventive Medicine \& Institute of Health Services Research, Yonsei University of College of Medicine, Seoul, Korea. 50-1 Yonsei-ro, Seodaemun-gu, Seoul, 120-752, Republic of Korea. Tel: +82-2-2228-1862, Fax: +82-2-392-8133, e-mail: ecpark@yuhs.ac. Jung-Gu Kang, MD, PhD, Department of Surgery, National Health Insurance Service Ilsan Hospital, Goyang, Korea. 100 Ilsan-ro, Ilsandong-gu, Goyang-si, Gyeonggi-do, 410-719, Republic of Korea. Tel: +82-31-900-0010, Fax: +82-31-900-0343, e-mail: kangski@nhimc.or.kr

(C) Ivyspring International Publisher. Reproduction is permitted for personal, noncommercial use, provided that the article is in whole, unmodified, and properly cited. See http://ivyspring.com/terms for terms and conditions.

Received: 2015.10.29; Accepted: 2016.01.22; Published: 2016.03.21

\begin{abstract}
Purpose: The colorectal cancer (CRC) is the third leading cause of death in Korea. Ulcerative colitis (UC) is regarded as a risk factor of CRC. The aim of study is to confirm the incidence of CRC among subjects with and without a diagnosis of UC based on a sample of the Korean population. This study identified the effect of UC on incidence of CRC in Korea.

Method: The data were from the population-based cohort containing National Health Insurance (NHI) claims from 2002 to 2013. We washed out first year (2002) for newly detected cases. Subjects who were under 20 years of age, diagnosed UC and CRC in 2002 development of CRC before diagnosis of UC since 2003, were excluded from analyses. Among 745,641 subjects during 11 years of follow-up (2003-2013), 7,448 patients with CRC were newly detected. Cox proportional hazard regression model was used to estimate the hazard ratio (HR) of UC for CRC incidence. Confounding variables including gender, baseline age, type of social security, income level, residence, Charlson Comorbidity Index, hypertension and diabetes mellitus were incorporated into the model.

Results: Overall annual incidence of UC and CRC were 6.7 and 95.4 per 100,000 during 11 years (2003 2013), respectively. Among 522 of newly detected UC cases, CRC incident cases were 12 cases during 11 years. The effects were stronger for male. Advancing age and Charlson Comorbidity Index, hypertension and diabetes mellitus increased the risk of CRC. This study showed that the adjusted hazard ratio of UC in incidence of CRC is 1.92 ( $95 \%$ confidence interval: 1.09-3.38). Also, male patients with UC have more HR than female patients with UC.

Conclusion: The results of this study showed that patients with UC are the high risk group in incidence of CRC. Furthermore, the effects of $U C$ in male patients are higher than those in female. The future study is needed to identify the effect of UC on mortality of CRC.
\end{abstract}

Key words: Colorectal cancer, ulcerative colitis, Korea, population-based cohort study

\section{Introduction}

The crude incidence rate per 100,000 of colorectal cancer (CRC) of 2012 is 57.6 (male: 69.3; female 45.9) that is the third highest occurring cancer in Korea, and annual percentage change was 5.3\% (male: 5.7\%, female: 4.3\%) during 14 years (1999 - 2012).[1] The crude death rate per 100,000 of CRC of 2012 was 16.2 
(male: 18.5; female: 13.8) that is the fourth common cause of cancer death.

The incidence of colorectal cancer has increased by 2 to 4 times during the past few decades in many Asian countries, including South Korea, China and Japan.[2] One of the reasons for increasing CRC is changes in dietary habits and lifestyle.[3, 4] Increased consumption of meat and animal fat might be a reason for rising incidence of colorectal cancer.

The incidence rate of CRC was high in patients with long-term ulcerative colitis (UC).[5-7] The prevalence for UC was higher in Western countries than in Asian countries.[8-11] Even though the prevalence in Western countries has begun to stabilize, the prevalence of UC in Asia is steadily increasing even now.[9-11] Recent studies on UC effects on incidence of CRC are conducted in Eastern countries. Registration program for Rare Intractable Disease (RID), including UC, was established in 2006. According to registration program, annual incidence for UC was 4.6 per 100,000.[12]

While the incidence of UC in Korea is still lower than those in Western countries, it is rapidly increasing.[13] It is anticipated that the incidence of UC-associated CRC will also increase. It is important to identify risk factors that influence developing CRC. The purpose of this study was to identify the association between UC and CRC using nationwide population-based cohort data in Korea.

\section{Method}

\section{Data and Study Population}

National Health Insurance Service (NHIS) has established the nationwide cohort containing medical care claims from 2002, the baseline year. The number of cohort population was 1,025,340 accounting for about $2 \%$ of total Korean population. The cohort was followed until 2013. The sampling method is a stratified sampling by gender, age, and income level. Gender and age were categorized into 2 (male, female) and 18 (0, 1 79 (5yrs), 80+). Income level was categorized into 41 (medical aid: 1, industrial worker (IW): 20, self-employee (SE): 20). Total stratified categories were 1,476 strata.

We washed out first year (2002) for newly detected cases. Subjects who were under 20 years of age $(n=278,524)$, diagnosed UC $(n=103)$ and CRC $(n=1,029)$ in 2002, and development of CRC before diagnosis of UC since $2003(n=64)$ were excluded from analyses (figure 1).

Thus, the final sample included 745,641 subjects: 366,251 male (49.1\%), 379,390 female (50.9\%). The data was observed for $7,807,280$ person-years in subject. All components and procedures of this study were approved by the Institutional Review Board (IRB) of National Health Insurance Medical Center (NHIMC) (IRB File No.: NHIMC 2015-07-029). This study used National Sample Cohort data (NHIS-2016-2-026), provided by NHIS.

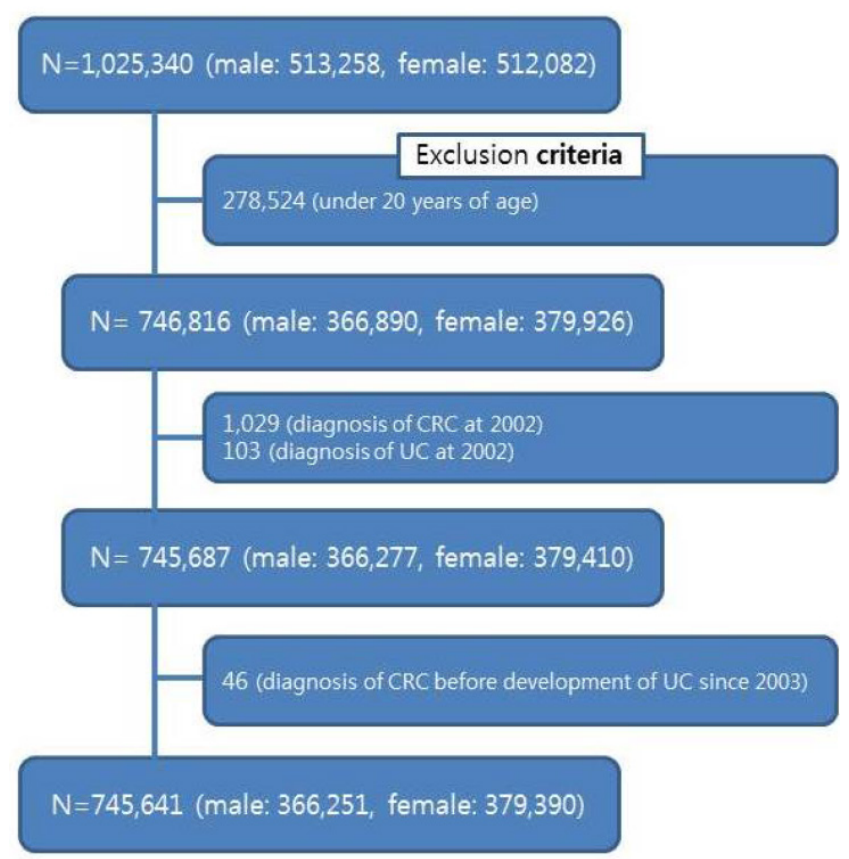

Figure 1. Flowchart of the subjects included for analysis

\section{Study Variables}

The diagnosis of CRC was a dependent variable. The CRC consists of malignant neoplasm of colon (C18), malignant neoplasm of rectosigmoid junction (C19) and malignant neoplasm of rectum (C20). CRC is a disease originating from the epithelial cells lining the colon or rectum of the gastrointestinal tract.

The diagnosis of UC was an independent variable. According to the 10th version of International Classification of Diseases (ICD-10), UC was designated with the code of main sick K51. The annual incidence of UC was 4.6 per 100,000 during 7 years (2006-2012).[12] On average, patients with UC have used clinics or hospitals 6.4 times per year in Korea. Based on annual incidence and utilization, the patients with UC were defined as visiting clinics or hospitals $\geq 4$ times annually.

Confounding variables included gender, baseline age, type of social security, income level, residence, Charlson Comorbidity Index (CCI), $[14,15]$ hypertension and diabetes mellitus. Age was divided to 4 groups (20-34, 35-49, 50-64, 65 and over years). The type of social security consists of medical aid and health insurance in Korea. Health insurance was divided into industrial worker (IW) and self-employer (SE). Income level was recoded into 5 categories, from 
quintile 1 (low) to quintile 5 (high), according to insurance premiums of householders. The residence was divided into capital city (Seoul), big cities, medium and small cities and rural areas. The CCI was recoded into 3 categories $(0,1, \geq 2)$. The hypertension and diabetes mellitus were defined as cases of subjects diagnosed with I10 I15 and E10 E14 in 2003. Survival time was the number of months between the baseline and the event of CRC.

Table 1. General characteristics of subjects, according to presence of colorectal cancer. Unit: N, (\%).

\begin{tabular}{|c|c|c|c|c|c|}
\hline & & Total & $\begin{array}{l}\text { With } \\
\text { No } \\
\text { Cancer }\end{array}$ & $\begin{array}{l}\text { With } \\
\text { Cancer }\end{array}$ & p-value \\
\hline Total & & 745,641 & $\begin{array}{l}738,193 \\
(99.0) \\
\end{array}$ & $\begin{array}{l}7,448 \\
(1.0) \\
\end{array}$ & \\
\hline \multirow{2}{*}{ Gender } & Male & 366,251 & $\begin{array}{l}362,047 \\
(98.8)\end{array}$ & $\begin{array}{l}4,204 \\
(1.2)\end{array}$ & $<.0001$ \\
\hline & Female & 379,390 & $\begin{array}{l}376,146 \\
(99.1)\end{array}$ & $\begin{array}{l}3,244 \\
(0.9)\end{array}$ & \\
\hline \multirow{4}{*}{ Age } & $20 \sim 34$ & 269,032 & $\begin{array}{l}268,630 \\
(99.8)\end{array}$ & $\begin{array}{l}402 \\
(0.2)\end{array}$ & $<.0001$ \\
\hline & $35 \sim 49$ & 257,534 & $\begin{array}{l}255,684 \\
(99.3)\end{array}$ & $\begin{array}{l}1,850 \\
(0.7)\end{array}$ & \\
\hline & $50 \sim 64$ & 139,828 & $\begin{array}{l}136,752 \\
(97.8)\end{array}$ & $\begin{array}{l}3,076 \\
(2.2)\end{array}$ & \\
\hline & $\geq 65$ & 79,247 & $\begin{array}{l}77,127 \\
(97.3)\end{array}$ & $\begin{array}{l}2,120 \\
(2.7)\end{array}$ & \\
\hline \multirow{3}{*}{$\begin{array}{l}\text { Type of } \\
\text { social } \\
\text { security }\end{array}$} & Medical aid & 22,038 & $\begin{array}{l}21,854 \\
(99.2)\end{array}$ & $\begin{array}{l}184 \\
(0.8)\end{array}$ & 0.0040 \\
\hline & $\begin{array}{l}\text { Health } \\
\text { insurance (IW) }\end{array}$ & 362,785 & $\begin{array}{l}359,050 \\
(99.0)\end{array}$ & $\begin{array}{l}3,735 \\
(1.0)\end{array}$ & \\
\hline & $\begin{array}{l}\text { Health } \\
\text { insurance (SE) }\end{array}$ & 360,818 & $\begin{array}{l}357,289 \\
(99.0)\end{array}$ & $\begin{array}{l}3,529 \\
(1.0)\end{array}$ & \\
\hline \multirow{5}{*}{ Income level } & 1 quintile(low) & 123,699 & $\begin{array}{l}122,563 \\
(99.1)\end{array}$ & $\begin{array}{l}1,136 \\
(0.9)\end{array}$ & $<.0001$ \\
\hline & 2 quintile & 121,352 & $\begin{array}{l}120,325 \\
(99.2)\end{array}$ & $\begin{array}{l}1,027 \\
(0.8)\end{array}$ & \\
\hline & 3 quintile & 144,515 & $\begin{array}{l}143,287 \\
(99.2)\end{array}$ & $\begin{array}{l}1,228 \\
(0.8)\end{array}$ & \\
\hline & 4 quintile & 166,932 & $\begin{array}{l}165,322 \\
(99.0)\end{array}$ & $\begin{array}{l}1,610 \\
(1.0)\end{array}$ & \\
\hline & 5 quintile(high) & 189,143 & $\begin{array}{l}186,696 \\
(98.7)\end{array}$ & $\begin{array}{l}2,447 \\
(1.3)\end{array}$ & \\
\hline \multirow{4}{*}{ Residence } & Seoul & 163,896 & $\begin{array}{l}162,051 \\
(98.9)\end{array}$ & $\begin{array}{l}1,845 \\
(1.1)\end{array}$ & $<.0001$ \\
\hline & Big cities & 194,830 & $\begin{array}{l}193,071 \\
(99.1)\end{array}$ & $\begin{array}{l}1,759 \\
(0.9)\end{array}$ & \\
\hline & $\begin{array}{l}\text { Medium, small } \\
\text { Cities }\end{array}$ & 305,887 & $\begin{array}{l}303,063 \\
(99.1)\end{array}$ & $\begin{array}{l}2,824 \\
(0.9)\end{array}$ & \\
\hline & Rural area & 81,028 & $\begin{array}{l}80,008 \\
(98.7)\end{array}$ & $\begin{array}{l}1,020 \\
(1.3)\end{array}$ & \\
\hline \multirow{3}{*}{$\begin{array}{l}\text { Charlson } \\
\text { Comorbidity } \\
\text { Index }\end{array}$} & 0 & 549,311 & $\begin{array}{l}544,897 \\
(99.2)\end{array}$ & $\begin{array}{l}4,414 \\
(0.8)\end{array}$ & $<.0001$ \\
\hline & 1 & 126,353 & $\begin{array}{l}124,718 \\
(98.7)\end{array}$ & $\begin{array}{l}1,635 \\
(1.3)\end{array}$ & \\
\hline & $\geq 2$ & 69,977 & $\begin{array}{l}68,578 \\
(98.0)\end{array}$ & $\begin{array}{l}1,399 \\
(2.0)\end{array}$ & \\
\hline \multirow{2}{*}{ Hypertension } & Non-Diagnosed & 682,923 & $\begin{array}{l}676,993 \\
(99.1)\end{array}$ & $\begin{array}{l}5,930 \\
(0.9)\end{array}$ & $<.0001$ \\
\hline & Diagnosed & 62,718 & $\begin{array}{l}61,200 \\
(97.6)\end{array}$ & $\begin{array}{l}1,518 \\
(2.4)\end{array}$ & \\
\hline \multirow{2}{*}{$\begin{array}{l}\text { Diabetes } \\
\text { mellitus }\end{array}$} & Non-Diagnosed & 716,027 & $\begin{array}{l}709,304 \\
(99.1)\end{array}$ & $\begin{array}{l}6,723 \\
(0.9)\end{array}$ & $<.0001$ \\
\hline & Diagnosed & 29,614 & $\begin{array}{l}28,889 \\
(97.5)\end{array}$ & $\begin{array}{l}725 \\
(2.5)\end{array}$ & \\
\hline \multirow{2}{*}{$\begin{array}{l}\text { Ulcerative } \\
\text { colitis }\end{array}$} & Non-Diagnosed & 745,119 & $\begin{array}{l}737,683 \\
(99.0)\end{array}$ & $\begin{array}{l}7,436 \\
(1.0)\end{array}$ & 0.0028 \\
\hline & Diagnosed & 522 & $\begin{array}{l}510 \\
(97.7)\end{array}$ & $12(2.3)$ & \\
\hline
\end{tabular}

IW: industrial worker, SE: self-employee

\section{Statistical Analysis}

We compared independent variables using $x^{2}$-test according to the presence of CRC. The results were expressed as frequency (\%). After performing preliminary analyses, we used Cox proportional hazard regression model to estimate the hazard ratio (HR) for the incidence of CRC. Covariates included baseline age (ref: 20-34 years old), type of social security (ref: Health insurance (IW)), income level (ref: 1 quintile), residence (ref: rural areas), CCI (ref: 0), hypertension (ref: non-diagnosed), diabetes mellitus (ref: non-diagnosed). Kaplan-Meier survival curve method was conducted to determine probability of incidence for group with UC relative to the reference group (non-diagnosed). Statistical analysis was performed using the SAS version 9.2. P-value $<0.05$ was considered to be significant.

\section{Results}

Baseline characteristics of subjects were shown according to incidence of CRC (Table 1). There were 7,448 new cases of CRC during 11 years (2003 2013), 4,204 of which occurred in male and 3,244 of which occurred in female. The incidence of CRC was higher in male than in female. CRC developed in $2.3 \%$ of the UC group and $1.0 \%$ in the non-UC group. Figure 2 shows the difference in development of CRC according to diagnosis of UC. Risk of CRC was over 2 fold higher in subjects with UC. The incidence of UC was 6.7 per 100,000 from 2003 to 2013. The incidence of CRC was 95.4 per 100,000 from 2003 to 2013. 12 of the patients with UC $(n=522)$ were diagnosed CRC. Overall, annual incidence of CRC in male and female were 110.2 and 81.2 per 100,000. Average durations at CRC diagnosis of patients with UC were 3.39 year.

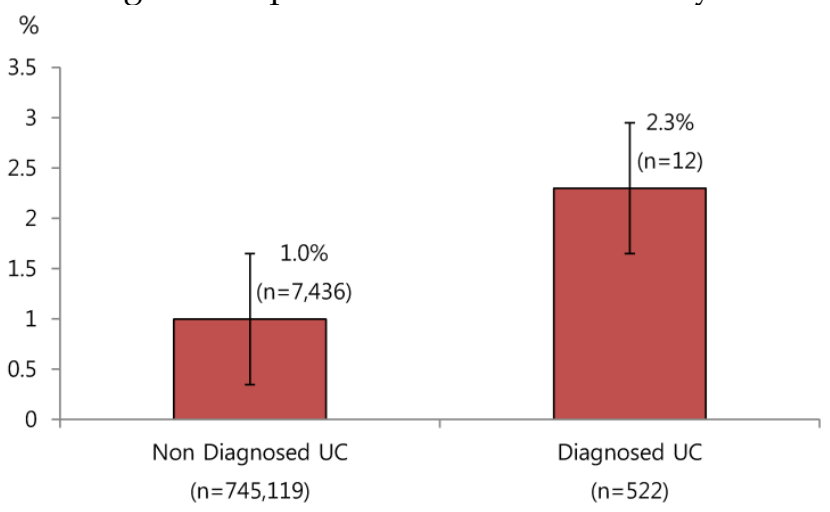

Figure 2. Difference in development of CRC according to diagnosis of UC

Table 2 showed the risk factors of being diagnosed with CRC during the follow-up period. HR of UC in CRC incidence of female (0.63 (95\% confidence interval (CI): 0.60-0.65)) was lower than male. HRs of age group steadily increased in CRC 
incidence (4.73 (95\% CI: 4.24-5.27) in 30-49 years old, 14.40 (95\%.CI: 12.96-16.00) in 50-64 years old, 22.39 (95\% CI: 20.04-25.02) in 65 years old and over) than reference group (20-34 years old). HR medical aid group was 0.66 (95\% CI: 0.56-0.78) than health insurance IW group. HR of highest income level was 1.18 (95\% CI: 1.10-1.28) than the lowest income group. HR of group residing in Seoul was 1.18 (95\% CI: 1.09-1.28) than group residing in rural area. HRs of group with $\mathrm{CCI}=1$ and $\geq 2$ were $1.12(95 \% \mathrm{CI}$ : 1.05-1.18) and 1.29 (95\% CI: 1.20-1.37) than group with $\mathrm{CCI}=0$, respectively. HRs of group with hypertension and diabetes mellitus were 1.13 (95\% CI: 1.06-1.20) and 1.15 (95\% CI: 1.06-1.25) than group of healthy subjects, respectively. HR of patients with UC was 1.92 (95\% CI: 1.09-3.38) than group without UC in incidence of CRC.

Figure 3 showed the results of Kaplan-Meier survival curves. The incidence probability of patients with UC was higher than the group without UC. The incidence probability of male with UC was higher than that of female with UC.
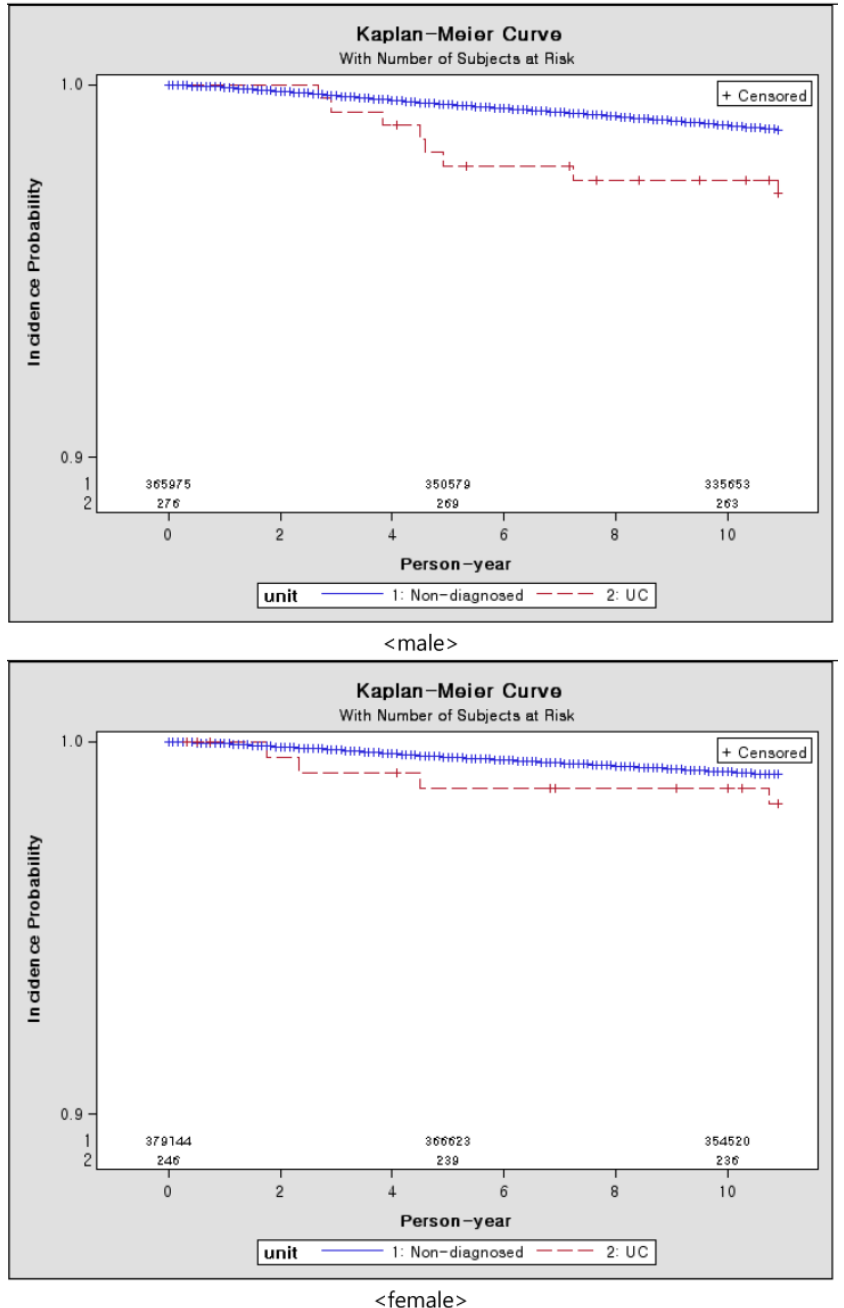

Figure 3. Kaplan-Meier curve of subjects by gender over 10 years, according to presence of ulcerative colitis
Table 2. Risk factor influencing the incidence of colorectal cancer

\begin{tabular}{|c|c|c|}
\hline & HR & $95 \% \mathrm{CI}$ \\
\hline Gender (ref: Male) & 1.00 & \\
\hline Female & 0.63 & $(0.60-0.65)$ \\
\hline Age (ref: $20 \sim 34$ ) & 1.00 & \\
\hline $35 \sim 49$ & 4.73 & $(4.24-5.27)$ \\
\hline $50 \sim 64$ & 14.40 & $(12.96-16.00)$ \\
\hline$\geq 65$ & 22.39 & $(20.04-25.02)$ \\
\hline $\begin{array}{l}\text { Type of social security (ref: Health } \\
\text { insurance_IW) }\end{array}$ & 1.00 & \\
\hline Medical aid & 0.66 & $(0.56-0.78)$ \\
\hline Health insurance(SE) & 0.96 & $(0.91-1.00)$ \\
\hline Income level (ref: 1 quintile) & 1.00 & \\
\hline 2 quintile & 1.04 & $(0.95-1.13)$ \\
\hline 3 quintile & 1.03 & $(0.95-1.13)$ \\
\hline 4 quintile & 1.06 & $(0.98-1.15)$ \\
\hline 5 quintile (high) & 1.18 & $(1.10-1.28)$ \\
\hline Residence (ref: Rural area) & 1.00 & \\
\hline Seoul & 1.18 & $(1.09-1.28)$ \\
\hline Big cities & 0.96 & $(0.88-1.03)$ \\
\hline Medium, small Cities & 0.95 & $(0.89-1.03)$ \\
\hline Charlson Comorbidity Index (ref: 0) & 1.00 & \\
\hline 1 & 1.12 & $(1.05-1.18)$ \\
\hline$\geq 2$ & 1.29 & $(1.20-1.37)$ \\
\hline Hypertension (ref: Non-diagnosed) & 1.00 & \\
\hline Diagnosed & 1.13 & $(1.06-1.20)$ \\
\hline Diabetes mellitus (ref: Non-diagnosed) & 1.00 & \\
\hline Diagnosed & 1.15 & $(1.06-1.25)$ \\
\hline UC (ref: Non-diagnosed) & 1.00 & \\
\hline Diagnosed & 1.92 & $(1.09-3.38)$ \\
\hline
\end{tabular}

IW: industrial worker, SE: self-employee

\section{Discussion}

This study was conducted to identify the UC effect on the CRC incidence. This study confirms previous findings that UC patients have a higher frequency of CRC than non-UC patients. Furthermore, male UC patients are at higher risk than female UC patients.

According to results, the annual incidence of UC and CRC were 6.7 and 95.4 per 100,000 during 11 years (2003 2013). In previous study using registration program for RID in Korea, the annual incidence of UC was 4.6 per 100,000 during 7 years (2006 2012).[12] The crude incidence rate per 100,000 of CRC of 2012 was 57.6 (male: 69.3; female 45.9) in 2012.[1] The reason why incidence of UC and CRC in this study might have excluded subjects under 20 years of age from analysis, is that subjects who were less than 20 years of age account for about $25 \%$ of the entire population.

CRC most frequently results from mutations in the Wnt signaling pathways that increases signaling activity. The mutations occur in the intestinal crypt stem cell.[16] The risk factors of CRC include male gender, increasing age, high intake of fat, alcohol or red meat, obesity, income, smoking, a lack of physical exercise, and family history of CRC.[17-19] The UC is associated with development of CRC.[5-7, 19, 20] The difference in result of analyses was explained by different methodology, target populations and follow-up period. 
A meta-analysis on the incidence of UC-associated CRC found that cumulative incidence of CRC was $2 \%$ at 10 -year, $8 \%$ at 20 -year and $18 \%$ at 30-year follow-up.[21] In case of Korea, the cumulative incidence of UC-associated CRC was $0.7 \%$ at 10 -year, $7.9 \%$ at 20 -year, and $33.2 \%$ at 30 -year follow-up.[22] According to the results, the cumulative incidence of UC-associated CRC was 2.3\% at 11-year follow-up.

Some epidemiologic studies have shown a higher risk of CRC in male than in female. This difference in risk of CRC between genders is not easily explained.[19] Increasing age is associated with an increased risk of CRC.[18] Socio-demographic indicators, such as income and residence might partially explain the increased incidence of CRC.[17, 23] Furthermore, the HR of CRC of the highest income level is significantly higher than that of lowest income level. Regional differences in screening also might affect detection of CRC. Risk factors associated with incidence of CRC are diagnoses of hypertension and diabetes mellitus.[18, 24] Finding from this study revealed that patients with hypertension or diabetes mellitus might be more likely to be diagnosed as CRC than healthy people without hypertension or diabetes mellitus.

In Korea, the target cancers of NCSP (National Cancer Screening Program) include stomach cancer, breast cancer, CRC, liver cancer, and cervical cancer. It is recommended for individuals aged $\geq 50$ years to get CRC screening on a yearly basis. CRC screenings are performed for screening items stipulated by the health screening implementation standards such as Fecal Occult Blood Test (FOBT), double-contrast examination of the colon, colonoscopy exam, and biopsy. Total inspection rate of cancer screening and inspection rate of CRC screening were $43.5 \%$ and $30.7 \%$ in 2013.[25] The inspection rate of CRC screening was lowest among the cancer screenings.

There are a number of diseases related to UC. Some studies found a highly increased risk for lymphoma and leukemia in patients with UC.[26, 27] The patients with UC have an increased risk of developing connective tissue and brain cancer in Sweden.[28] There was an increased risk of hepatobiliary cancer and non-melanoma skin cancer among patients with UC.[19, 29, 30] In addition, an Italian population-based study showed an increased risk for Hodgkin's disease among patients with UC.[31]

The source used in analysis was population-based representative data containing all medical claims and checkup results of population from 2002 to 2013. A number of studies have been carried out to identify the cause of disease utilizing accumulated data via electronic data interchange (EDI) in Korea.

This study had the following limitations. First, data based on claims data included only information on each episode of health care utilization and expenditure. Claim data used in analysis did not include clinical findings and disease severity. The variables used in this study were limited. Also, important co-variates associated with risk of CRC in UC are not available for the cohort thus limiting the value of the findings. The factors that influenced association between UC and CRC were age at initial diagnosis, life style, and family history of CRC.[32-34] Second, follow-up period was short (11 years), which might have precluded the detection of significant effects of UC on subsequent incidence of CRC. The incidence of CRC begins to increase 8 or 10 years after the initial diagnosis of UC.[19, 30, 35]

In conclusion, the cancer caused financial and psychological burden to the caregiver, as well as pain of patients. CRC is a disease attributable to inappropriate behavior patterns and lifestyle. Prevention is the best cure for cancer. To reduce the incidence of CRC in patients with UC, it is important to identify predictive and protective factors for CRC. Developing cancer prevention strategies might be helpful in containing the incidence of cancer to selected high-risk groups.

\section{Abbreviations}

CRC: Colorectal Cancer; UC: Ulcerative Colitis; RID: Rare Intractable Disease; NHIS: National Health Insurance Service; IW: Industrial Worker; SE: Self-Employee; NHIMC: National Health Insurance Medical Center; ICD: International Classification of Diseases; CCI: Charlson Comorbidity Index; HR: Hazard Ratio; NCSP: National Cancer Screening Program; FOBT: Fecal Occult Blood Test; EDI: Electronic Data Interchange.

\section{Acknowledgements}

The study was supported by the grant of the Institute of Health Insurance \& Clinical Research of NHIMC.

\section{Competing Interests}

The authors have declared that no competing interest exists.

\section{References}

1. Jung KW, Won YJ, Kong HJ, Oh CM, Cho H, Lee DH, et al. Cancer statistics in Korea: incidence, mortality, survival, and prevalence in 2012. Cancer research and treatment : official journal of Korean Cancer Association. 2015; 47: 127-41.

2. Sung JJ, Lau JY, Goh KL, Leung WK, Asia Pacific Working Group on Colorectal C. Increasing incidence of colorectal cancer in Asia: implications for screening. The Lancet Oncology. 2005; 6: 871-6. 
3. Chiu BC, Ji BT, Dai Q, Gridley G, McLaughlin JK, Gao YT, et al. Dietary factors and risk of colon cancer in Shanghai, China. Cancer epidemiology, biomarkers \& prevention : a publication of the American Association for Cancer Research, cosponsored by the American Society of Preventive Oncology. 2003; 12: 201-8.

4. Yiu HY, Whittemore AS, Shibata A. Increasing colorectal cancer incidence rates in Japan. International journal of cancer Journal international du cancer. 2004; 109: 777-81.

5. Greenstein AJ, Sachar DB, Smith H, Janowitz HD, Aufses AH, Jr. A comparison of cancer risk in Crohn's disease and ulcerative colitis. Cancer. 1981; 48: 2742-5.

6. Isbell G, Levin B. Ulcerative colitis and colon cancer. Gastroenterology clinics of North America. 1988; 17: 773-91.

7. Chambers WM, Warren BF, Jewell DP, Mortensen NJ. Cancer surveillance in ulcerative colitis. The British journal of surgery. 2005; 92: 928-36.

8. Yang SK, Loftus EV, Jr., Sandborn WJ. Epidemiology of inflammatory bowel disease in Asia. Inflammatory bowel diseases. 2001; 7: 260-70.

9. Baumgart DC, Carding SR. Inflammatory bowel disease: cause and immunobiology. Lancet. 2007; 369: 1627-40.

10. Thia KT, Loftus EV, Jr., Sandborn WJ, Yang SK. An update on the epidemiology of inflammatory bowel disease in Asia. The American journal of gastroenterology. 2008; 103: 3167-82.

11. Asakura K, Nishiwaki Y, Inoue N, Hibi T, Watanabe M, Takebayashi T. Prevalence of ulcerative colitis and Crohn's disease in Japan. Journal of gastroenterology. 2009; 44: 659-65.

12. Kim HJ, Hann HJ, Hong SN, Kim KH, Ahn IM, Song JY, et al. Incidence and natural course of inflammatory bowel disease in Korea, 2006-2012: a nationwide population-based study. Inflammatory bowel diseases. 2015; 21: 623-30.

13. Yang SK, Yun S, Kim JH, Park JY, Kim HY, Kim YH, et al. Epidemiology of inflammatory bowel disease in the Songpa-Kangdong district, Seoul, Korea, 1986-2005: a KASID study. Inflammatory bowel diseases. 2008; 14: 542-9.

14. Charlson ME, Pompei P, Ales KL, MacKenzie CR. A new method of classifying prognostic comorbidity in longitudinal studies: development and validation. Journal of chronic diseases. 1987; 40: 373-83.

15. Sundararajan V, Henderson T, Perry C, Muggivan A, Quan H, Ghali WA. New ICD-10 version of the Charlson comorbidity index predicted in-hospital mortality. Journal of clinical epidemiology. 2004; 57: 1288-94.

16. Abdul Khalek FJ, Gallicano GI, Mishra L. Colon cancer stem cells. Gastrointestinal cancer research : GCR. 2010;: S16-23.

17. Guimaraes RM, Rocha PG, Muzi CD, Ramos Rde S. Increase income and mortality of colorrectal cancer in Brazil, 2001-2009. Arquivos de gastroenterologia. 2013; 50: 64-9.

18. Qin M, Ma LQ, Tan J, Chen YR, Zhu LR, Lin R, et al. Risk factors for colorectal neoplasms based on colonoscopy and pathological diagnoses of Chinese citizens: a multicenter, case-control study. International journal of colorectal disease. 2015; 30: 353-61.

19. Karlen P, Lofberg R, Brostrom O, Leijonmarck CE, Hellers G, Persson PG. Increased risk of cancer in ulcerative colitis: a population-based cohort study. The American journal of gastroenterology. 1999; 94: 1047-52.

20. Lakatos L, Mester G, Erdelyi Z, David G, Pandur T, Balogh M, et al. Risk factors for ulcerative colitis-associated colorectal cancer in a Hungarian cohort of patients with ulcerative colitis: results of a population-based study. Inflammatory bowel diseases. 2006; 12: 205-11.

21. Eaden JA, Abrams KR, Mayberry JF. The risk of colorectal cancer in ulcerative colitis: a meta-analysis. Gut. 2001; 48: 526-35.

22. Kim BJ, Yang SK, Kim JS, Jeen YT, Choi H, Han DS, et al. Trends of ulcerative colitis-associated colorectal cancer in Korea: A KASID study. Journal of gastroenterology and hepatology. 2009; 24: 667-71.

23. Perdue DG, Perkins C, Jackson-Thompson J, Coughlin SS, Ahmed F, Haverkamp DS, et al. Regional differences in colorectal cancer incidence, stage, and subsite among American Indians and Alaska Natives, 1999-2004. Cancer. 2008; 113: 1179-90.

24. Kramer HU, Schottker B, Raum E, Brenner H. Type 2 diabetes mellitus and colorectal cancer: meta-analysis on sex-specific differences. European journal of cancer. 2012; 48: 1269-82.

25. NHIS. National Health Screening Statistical Yearbook 2013. 2014.

26. Greenstein AJ, Gennuso R, Sachar DB, Heimann T, Smith H, Janowitz HD, et al. Extraintestinal cancers in inflammatory bowel disease. Cancer. 1985; 56: 2914-21.

27. Mir-Madjlessi SH, Farmer RG, Easley KA, Beck GJ. Colorectal and extracolonic malignancy in ulcerative colitis. Cancer. 1986; 58: 1569-74.

28. Ekbom A, Helmick C, Zack M, Adami HO. Extracolonic malignancies in inflammatory bowel disease. Cancer. 1991; 67: 2015-9.

29. Mellemkjaer L, Olsen JH, Frisch M, Johansen C, Gridley G, McLaughlin JK. Cancer in patients with ulcerative colitis. International journal of cancer Journal international du cancer. 1995; 60: 330-3

30. Bernstein CN, Blanchard JF, Kliewer E, Wajda A. Cancer risk in patients with inflammatory bowel disease: a population-based study. Cancer. 2001; 91: 854-62.

31. Palli D, Trallori G, Bagnoli S, Saieva C, Tarantino O, Ceroti M, et al. Hodgkin's disease risk is increased in patients with ulcerative colitis. Gastroenterology. 2000; 119: 647-53.

32. Nuako KW, Ahlquist DA, Mahoney DW, Schaid DJ, Siems DM, Lindor NM. Familial predisposition for colorectal cancer in chronic ulcerative colitis: a case-control study. Gastroenterology. 1998; 115: 1079-83.
33. Askling J, Dickman PW, Karlen P, Brostrom O, Lapidus A, Lofberg R, et al. Family history as a risk factor for colorectal cancer in inflammatory bowel disease. Gastroenterology. 2001; 120: 1356-62.

34. Brackmann S, Andersen SN, Aamodt G, Langmark F, Clausen OP, Aadland E, et al. Relationship between clinical parameters and the colitis-colorectal cancer interval in a cohort of patients with colorectal cancer in inflammatory bowel disease. Scandinavian journal of gastroenterology. 2009; 44: 46-55.

35. Langholz E, Munkholm P, Davidsen M, Binder V. Colorectal cancer risk and mortality in patients with ulcerative colitis. Gastroenterology. 1992; 103: $1444-51$ 